INTERNATIONAL HIGHER EDUCATION, No. 67, Spring, 2012

Pages 13-14

\title{
National Policies on Mobility in Europe
}

\author{
QueEnie LAM
}

Queenie Lam is project officer, of the Academic Cooperation Association, Brussels, Belgium. E-mail: secretariat@aca-secretariat.be. This article is based on Irina Ferencz and Bernd Waechter, eds., European and National Policies for Academic Mobility: Linking Rhetoric, Practice and Mobility Trends (Bonn: Lemmens, 2012).

Europe-the continent that brought us the wildly successful student-mobility program, ERASMUS (European Community Action Scheme for the Mobility of University Students), more than 20 years ago-may at first glance appear to be highly united in its enthusiasm for international student mobility. The situation on the ground, however, (in terms of both policy and practice) is much more complex than the "grand discourse" on European student mobility, of recent years, might seem to indicate.

This situation represents both a strength and a weakness. On the one hand, Europe (whether understood as a configuration of 27 European Union member states—or, the broader group of 47 Bologna process/European Higher Education Area signatory countries) presents a richly diverse higher education landscape. This variety clearly extends to the profiles presented by each country, when it comes to policies for international student mobility. Happily, this diversity allows different approaches to be tested-and accepted or rejected- 
according to unique national or institutional characteristics. The European Union works to help its member states moving toward the realization of a European Union-wide benchmark for mobility by 2020, following the endeavors of the European Higher Education Area to articulate its own set of mobility objectives for the rest of the decade. However, the lack of a systematic approach to mobility at the national level may prove to be a major stumbling block, on the road to achieving European-level policy goals.

\section{Mobility Policies In the European ConTeXt}

Mobility, when understood in the context of European higher education, is closely associated with the European Union's ERASMUS program-with good reason. Since its inception in the mid-1980s, ERASMUS has stood out as the largest and arguably the most "successful" funding program for short-term student exchange (hereinafter: credit mobility) in the world. With the introduction of other mobility initiatives, such as ERASMUS MUNDUS, mobility has acquired an array of new meanings, beyond intra-European credit mobility in the European Union's policy discourse. Attention is now being given to opportunities for non-European students to attain full degrees in Europe (hereinafter: incoming degree mobility) as well as academic/research staff mobility. However, recent research in this area, conducted by the Brussels-based Academic Cooperation Association, has found that these new mobility modes have not yet gained the same level of attention in national policy circles, as the longstanding credit mobility activities.

Despite the high importance attached to mobility by national governments, in general, few European countries have articulated a national 
policy to deal in a systematic manner with the different types of mobility now in evidence in their higher education systems, although many believe they have such policies in place. A handful of nations-among them, the Nordic countries (notably Finland and Denmark), the Netherlands, and two Baltics (Estonia and Lithuania) - may be said to acquire something close to a national-mobility policy. In most cases, though, where there is evidence of some national-level constructs concerning mobility, their elements are found scattered across a number of different policy documents and purviews, ranging from education and research to immigration and labor. The Academic Cooperation Association's research in this area finds that the breadth and depth of mobility policies vary to a great extent. Often it is even doubtful whether the national governments have a clear understanding of the distinctions between different mobility types (degree versus credit, incoming versus outgoing, etc.) when setting national-mobility priorities and targets.

\section{MOBILITY: INTERNATIONAL OR INTRA-EUROPEAN}

Up to now, clearly credit mobility in Europe has a strong intra-European orientation, while degree mobility meets a strong external dimension, aimed at third countries (i.e., non-European). However, both types of mobility are generally referred to as international mobility.

Outgoing credit mobility is the top priority for national governments in Europe, in contrast with outgoing degree mobility. Most countries clearly do not want to see outgoing degree mobility, fearing brain drain. Not surprisingly, however, a growing number of European national governments appear to be actively interested in incoming degree mobility, although this is not without its 
risks. On the one hand, attracting fee-paying degree students makes a good economic option, and is a trend seen clearly in such countries as the United Kingdom, Ireland, Malta, and Cyprus. However, others have registered deep concern about the high influx of students from neighboring countries into their national systems, with perceived burdens placed on local taxpayers and local students seeking access and a high-quality (i.e., not overcrowded) educational environment. Austria's experience with large numbers of incoming German students is a prime example of this dynamic. Nevertheless, many European countries still attach high priority to incoming degree mobility (presumably, from outside Europe)—with specific interest in $\mathrm{PhD}$ and master's degree students, which is in line with the dominant discourse of attracting talent for "enhancing innovation" and "strengthening the knowledge economy."

\section{MOVING TARGETS?}

The quantitative targets and geographical foci mentioned in European national discussions of mobility are defined in surprisingly vague terms. Agreement seems to be coalescing in many circles around the notion of aiming for 20 percent or more for outgoing mobility and around 10 percent for incoming mobility. The geographical locations of particular interest—for both sending and receiving students-include Europe itself (i.e., intra-European mobility), followed by Asia and the United States/Canada.

However, Europe's mobility aspirations are rarely defined in relation to any specific type of mobility. As a result, ambitious but vaguely defined mobility targets are seen as high as 50 percent, which left undefined could refer to 
mobility experiences as short as one week or mobility activities only tangentially related to study and/or research. Moreover, it is unclear whether countries aiming for 50 percent mobility aspire to have 50 percent of their annual cohort of students undertaking a study-abroad experience in a particular year or if 50 percent of their graduates within a certain time frame should have been mobile.

Similar loose ends are found with regard to geographic targets. While these objectives seem to be clearly identified, it is not always apparent which types of students might be the focus of these mobility actions. Without clear parameters, such targets remain largely symbolic signals of national aspiration, with little indicative value for guiding mobility development. The lack of clarity on these important specifics also makes comparing the mobility objectives across Europe exceedingly problematic.

\section{LAYING THE GROUNDWORK FOR 2014-2020}

The European Union is poised to introduce a new program in 2014-ERASMUS for All. Unlike the original ERASMUS, the new architecture foreseen by the European Union for cooperation in education and training through 2020 will likely encompass all levels of education-as well as, cooperation efforts with third countries, particularly those in the European Union's neighborhood region. This is likely to introduce further complexity into the concept of mobility in Europe, in light of the possible extension of the heretofore "Europe only" ERASMUS program to countries outside Europe and the inclusion of intraEuropean degree mobility at the master's level. As these developments unfold, careful reflection on the current state of affairs in European national policies on mobility is essential. More significantly, a systematic approach, based on clearly 
differentiated mobility types and well-defined targets among other key considerations, is most necessary for the formulation of robust national policies for advancing mobility. 